The implications of the recent study of CBT for the prevention of psychosis (Morrison et al, 2004) need to be realistically interpreted with this background.

First, two people were excluded from the cognitive therapy arm after the trial had begun, which would have led to a non-significant result. This should have been acknowledged in the abstract, as an abstract has the most impact with service planners.

Second, after 6 months of cognitive therapy, there was a decrease in the development of psychosis compared with the control arm; however, there was similar distress for both groups. Cognitive therapy for psychosis has an aim of decreasing the distress of psychosis as well as the formulation of an explanatory model for that psychosis. It may be that a reframed and normalised explanatory language was taught to the individuals at high risk, and this led to the decreased identification of symptoms at 12 months and the masking of a psychotic episode. This would not ultimately lead to a decrease in distressing psychosis, but to a later identification of psychosis and a possible delay in pharmacological treatment.

The possible risk of harm or hazard was ignored, with a clear bias against the use of medication expressed by the authors in the discussion. Furthermore, the editorial comment alluded to the possibility of premature publication (Tyrer, 2004), but it is the implication of harm which needs to be explicitly stated.

Marshal, M. \& Lockwood, A. (2004) Early intervention for psychosis (Cochrane review). Cochrane Library, Issue 3. Oxford: Update Software.

Morrison, A. P., French, P., Walford, L., et al (2004) Cognitive therapy for the prevention of psychosis in people at ultra-high risk: randomised controlled trial. British Journal of Psychiatry, 185, 291-297.

Tyrer, P. (2004) From the Editor's desk. British Journal of Psychiatry, 185, 360.

K. H. Marlowe Early Psychosis InterventionTeam (EPIT), Counties Manukau DHB, Hartford House, Papatoetoe, Auckland, New Zealand. E-mail: Karl.Marlowe@middlemore.co.nz

Author's reply: We welcome Dr Marlowe's comments on our paper and would like to respond to the issues that he identified. The Cochrane review to which he refers examined more traditional approaches to early intervention (i.e. from first episode onwards) rather than a preventive approach in people at high risk, so we are unsure of the relevance of this. Within the manuscript we clearly acknowledge that there were several methodological limitations, including the exclusion of two participants, but we were unable to incorporate these in the abstract as he suggests because of limitations of abstract length imposed by the Journal (indeed, we were asked to further reduce the abstract at proof stage).

We agree that cognitive therapy for psychosis (and the prevention of psychosis) has an aim of decreasing the distress of psychotic experiences as well as the formulation of an explanatory model for a person's difficulties. We also agree that a reframed and normalised explanatory language may be developed by the service users; however, it is unlikely that this would lead to a masking of a psychotic episode. Rather, it is intended to reduce the potential for catastrophic appraisals of psychotic experiences, which are very clearly implicated in the experience of distress (Chadwick \& Birchwood, 1994), and the development of normalising appraisals is at the heart of cognitive therapy for established psychosis (Morrison et al, 2003) and the prevention of psychosis alike (French \& Morrison, 2004). Even if such a masking were to occur, the assumption that this could cause harm clearly demonstrates a bias against the use of psychosocial interventions, as it suggests that only pharmacological treatments can reduce the potential harm that may result from an untreated psychotic episode, when there is evidence that psychological treatment is also important in this respect (de Haan $e t$ al, 2003).

We are accused of being biased against using antipsychotic medication; we certainly are against medication in a population who are yet to develop a psychotic disorder, for the ethical reasons outlined within our paper and elsewhere (Bentall \& Morrison, 2002). Finally, it is suggested that we avoid explicitly stating the possibility of harm arising from such an intervention; however, we clearly highlight the possibility of harm resulting from stigmatisation.

Bentall, R. P. \& Morrison, A. P. (2002) More harm than good: the case against using antipsychotic drugs to prevent severe mental illness. Journal of Mental Health, II, 35I-365.

Chadwick, P. \& Birchwood, M. (1994) The

omnipotence of voices: a cognitive approach to auditory hallucinations. British Journal of Psychiatry, 164, 190-201. de Haan, L., Linszen, D. H., Lenior, M. E., et al (2003) Duration of untreated psychosis and outcome of schizophrenia: delay in intensive psychosocial treatment versus delay in treatment with antipsychotic medication Schizophrenia Bulletin, 29, 34I-348.

French, P. \& Morrison, A. P. (2004) Cognitive Therapy for People at High-Risk of Psychosis. London: Wiley,

Morrison, A. P., Renton, J. C., Dunn, H., et al (2003) Cognitive Therapy for Psychosis: A Formulation-Based Approach. London: Psychology Press.

A. P. Morrison Department of Psychology University of Manchester, Coupland Street, Manchester MI3 9PL, UK. E-mail:

tony.morrison@psy.man.ac.uk

\section{Integration of psychiatric and physical health}

In The Netherlands the British Journal of Psychiatry is distributed among Dutch psychiatrists by courtesy of the pharmaceutical industry. For the October issue of the Dutch edition I was asked to write the editorial comment, to be circulated with the Journal as an accompanying letter. My focus is integrated psychiatry in medicine.

Reading the October issue I was struck by the lack of an integrated perspective. Current epidemiological findings underscore how the organisation of our healthcare system is epidemiologically unfair and does not take into account the frequent co-occurence of psychiatric disturbances and physical illness (Kendell, 2001; Royal College of Physicians \& Royal College of Psychiatrists, 2003). The fragmentation of care is seen as one of the major problems of current healthcare (Institute of Medicine, 2001); this applies with regard to treatment of physical disorders in mental healthcare and vice versa.

The editorial by Kingdon et al (2004) on the recommendations of the Council of Europe lacks such an integrated perspective. Among the recommendations the quality of physical care is not mentioned by the Council other than in relation to restraint, and this omission is not mentioned by Kingdon et al.

Similarly, the review by Thornicroft \& Tansella (2004) opens with the fact that depression leads to more disabilityadjusted life-years than cardiovascular disease and cancer, but it does not report their meaningful interrelation, for instance through compliance (DiMatteo et al, 2000). In the section 'Acute in-patient care' it is mentioned that patients with physical comorbidity should preferentially be seen in such facilities and not in community 